Session 5-3

\title{
Developing a Dynamics Simulation Tool for Student Exploration of Concepts
}

\author{
Luciana Barroso \& Jim Morgan \\ Zachry Department of Civil Engineering \\ Texas A\&M University
}

\begin{abstract}
Dynamics provides a tool for civil engineers to evaluate a changing world. The material presented in the dynamics course relies heavily on the pre-requisites and connects concepts in new ways. Knowledge transfer to dynamic principles is difficult even when students do see a connection to previous courses. Misconceptions are very persistent and cannot be easily debunked by standard instruction with lectures, textbooks, demonstrations or laboratories. Educators and researchers have looked at using computers to enhance classroom instruction ever since the technology made it feasible to do so. This is particularly effective for topics that involve motion of objects or other significant visual components that are not easily represented on a black board. Simulation programs also allow complex systems to be quickly and easily modeled and can be adapted to many different learning styles. The authors have collaborated in the development of a dynamics simulation software package that has the power and flexibility to handle the model systems normally encountered in a course in dynamics in order to address these issues. This software gives the student the ability to build, tune, simulate and evaluate a model all within a single environment. The software developed provides a "construction set" that students can use to build their own simulations of dynamic models and run them to observe their performance. This program is interactive and can be used in the classroom for demonstrations, in the laboratory for guided use, and on student's own computers for experimentation and to complete assignments. The computer simulations provide ample opportunity for them to learn in an environment that allows them to fail safely.
\end{abstract}

\section{Introduction}

Dynamics provides a tool for civil engineers to evaluate a changing world. In the traditional approach for teaching dynamics to undergraduates, many students think that dynamics is a collection of problem-specific tricks instead of a unified body of knowledge built upon a very limited number of basic equations and principles. Texts for the introductory dynamics courses "customarily downplay the pervasive nature of differential equations as dynamics natural language ${ }^{1}$." Combined with the lack of connection to civil engineering applications, students cannot see the purpose and relevance of this material ${ }^{1}$.

The civil engineering department at our university has adopted a course in Dynamics \& Vibrations as the standard introductory undergraduate dynamics course. The course emphasizes model development and the use of general kinematic equations and differential equations of motion for problem solving. Students enter this course with an exposure to: mechanics; free-body diagrams, equilibrium and energy conservation principles; calculus and differential equations; and numerical 
methods. An overall goal for students taking this course is to model, predict and evaluate the dynamic response of civil structures. An overview of the overall problem progression can be described as: (1) Identify the real physical system (e.g. building) and loads (e.g. earthquake); (2) create a simple physical model of the system (mass-spring-dashpot); (3) develop mathematical model that represents the physical behavior and loads; (4) find mathematical solution that represents the dynamic response; (5) utilize the mathematical solution to simulate and evaluate the dynamic motion of simple physical model; (6) evaluate the dynamic motion of real physical system² ${ }^{2}$

The material presented in the dynamics course relies heavily on the prerequisites and connects concepts in new ways. Without a good understanding of those topics, learning the new material is extremely difficult. A problem arises from students' expectation regarding the material presented in lower level courses that are frequently considered as weed-out courses. Since students do not immediately see the relevance of the material, they frequently forget that material immediately after the final exam. As such, exposure to the required material does not guarantee knowledge transfer to courses later in their degree program. From the student's perspective, each course is an individual entity that has minimal connection to others.

Knowledge transfer to dynamic principles is difficult even when students do see a connection to previous courses. The literature on student misconceptions in dynamic principles is quite rich $^{3}$. Misconceptions are very persistent and cannot be easily debunked by standard instruction with lectures, textbooks, demonstrations or laboratories ${ }^{4,5}$. A major challenge for students is that any intuition they developed for statics problems can lead to incorrect analysis of dynamics problems. So the disconnections occur between courses, topics, and the student's own experience, and the problem-solving progression discussed earlier breaks down. In evaluating the difficulties described above, the following basic pedagogical issues have been identified as underlying the difficulties most students have with this topic:

1. Forgetting, misconceptions and misapplication of prior knowledge leading to difficulties with knowledge transfer between courses

2. Difficulties developing models and connecting the response of those models to real system behavior

3. Critical thinking about complex problems and systems, both in how to break down a problem and identify appropriate simplifying assumptions, as well as how to evaluate their problem solution and system behavior

These issues are by no means unique to dynamics courses ${ }^{6}$. However, the nature of the material is such that these problems become more obvious in this class, and students cannot successfully complete the course without addressing these issues. The fundamental nature of these pedagogical issues is reflected by their close connection to key findings articulated in How People Learn ${ }^{7}$. The research synthesized indicates that if the learner's preconceptions (including misconceptions) about a particular topic are not brought to the surface, then new concepts will be poorly learned and misconceptions will remain. Addressing student misconceptions does not have to be presented in a negative or remedial context; pre-Newtonian concepts in mechanics have had wide appeal, including Galileo ${ }^{8}$. Used as a part of an active, inquiry based classroom, talking about misconceptions will be as natural as talking about learning styles ${ }^{9,10}$, or the fundamental principles in the syllabus ${ }^{11}$. The better students understand their own learning, the more successful they are likely to be ${ }^{12}$. 
Kolb’s Experiential Learning Model defines learning preferences in terms of both (a) how information is acquired (concrete experience or abstract conceptualization) and (b) how information is processed (active experimentation or reflective observation) ${ }^{13}$. Many engineering students fall in the range outside the boundary of traditional lecture ${ }^{14}$ :

- concrete (how course material relates to the real world)

- active (in an environment that allows them to fail safely)

Active learning is an attempt to expand the single one-size fits-all lecture approach to teaching to one which allows more students to operate in their comfort zone at least part of the time. Including demonstrations and active experiments expands the lecture to include the active students and provide ample opportunity for them to learn in an environment that allows them to fail safely.

Educators and researchers have looked at using computers to enhance classroom instruction ever since the technology made it feasible to do so. It is now widely accepted that computer aided instruction can help students gain a better understanding of the subject matter if implemented appropriately $^{15}$. This is particularly true for topics that involve motion of objects, three-dimensional structures or other significant visual components that are not easily represented on a black board. For example, engineering dynamics is the study of motion but this motion cannot be shown effectively using traditional teaching tools, including mechanical models, which are more qualitative but not quantitative ${ }^{16}$.

Several researchers have investigated the use of computers, specifically simulation and visualization technology, in education. Foley had shown that computer simulation and visualization can be very effective in enhancing student learning if the interface is based on education research ${ }^{17}$. Foley's study for middle school students learning thermodynamics also concluded that visualization tools facilitate understanding and retention of key concepts. Simulation programs also allow complex systems to be quickly and easily modeled and can be adapted to many different learning styles ${ }^{15}$.

\section{Implementation of Demonstrations}

Demonstrations can be very effective at engaging students, generating interest in a topic, and enhancing student learning. A key component to an effective demonstration is active student engagement throughout the entire process. This means students are involved in discussing the purpose of the demo; predicting what will happen during the demo; discussing who developed theories to help us understand what happens during the demo; and comparing observations to predictions, as opposed to simply passively watching a demonstration.

- Pre-activities: get them to commit

- During: keeps them engaged

- Post-activities: get them to explain - explicitly address misconceptions.

Observation by a faculty development professional of class sessions during which demonstrations took place gave evidence that the intended result—student engagement-did in fact occur. Because students were asked to predict what would happen prior to the demonstration, they were motivated to pay attention during the demonstration. Students in the back of the room stood up so that they 
could see more clearly what was happening. The instructor's questioning process before, during, and after the demonstration kept student attention focused on critical components of the demonstration. Further, students were asked to write predictions and write answers to post-demonstration questions and were given time to discuss observations and answers with peers. This helped to ensure that all students were engaged, not just the handful of students who are quick to participate during class.

\section{Dynamics Simulation Software: Tinker}

Computer-based materials can allow students to exercise their higher-level thinking skills (Analysis, Synthesis, and Evaluation). The main goal was to develop a software package for teaching purposes that could easily be used by both instructors and students. Visualization for educational purposes needs to (1) be designed for flexibility, (2) capture larger concepts, and (3) map to existing teaching and learning resources ${ }^{19}$. So the software needed to allow the easy creation of systems, which could then be easily customizable. Additionally, the software is designed to explicitly ask the students to make same choices they have to make when solving problem by hand. For example, they must choose the units and coordinate system to be used in solving the problem. Yet the students had to be able to easily switch to another option to investigate the consequences of their decision.

Figure 1 shows a screen capture of the opening screen of the software created, named Tinker. Before starting any model building, students must choose the units for the problem as well as the size of the working space for the model.

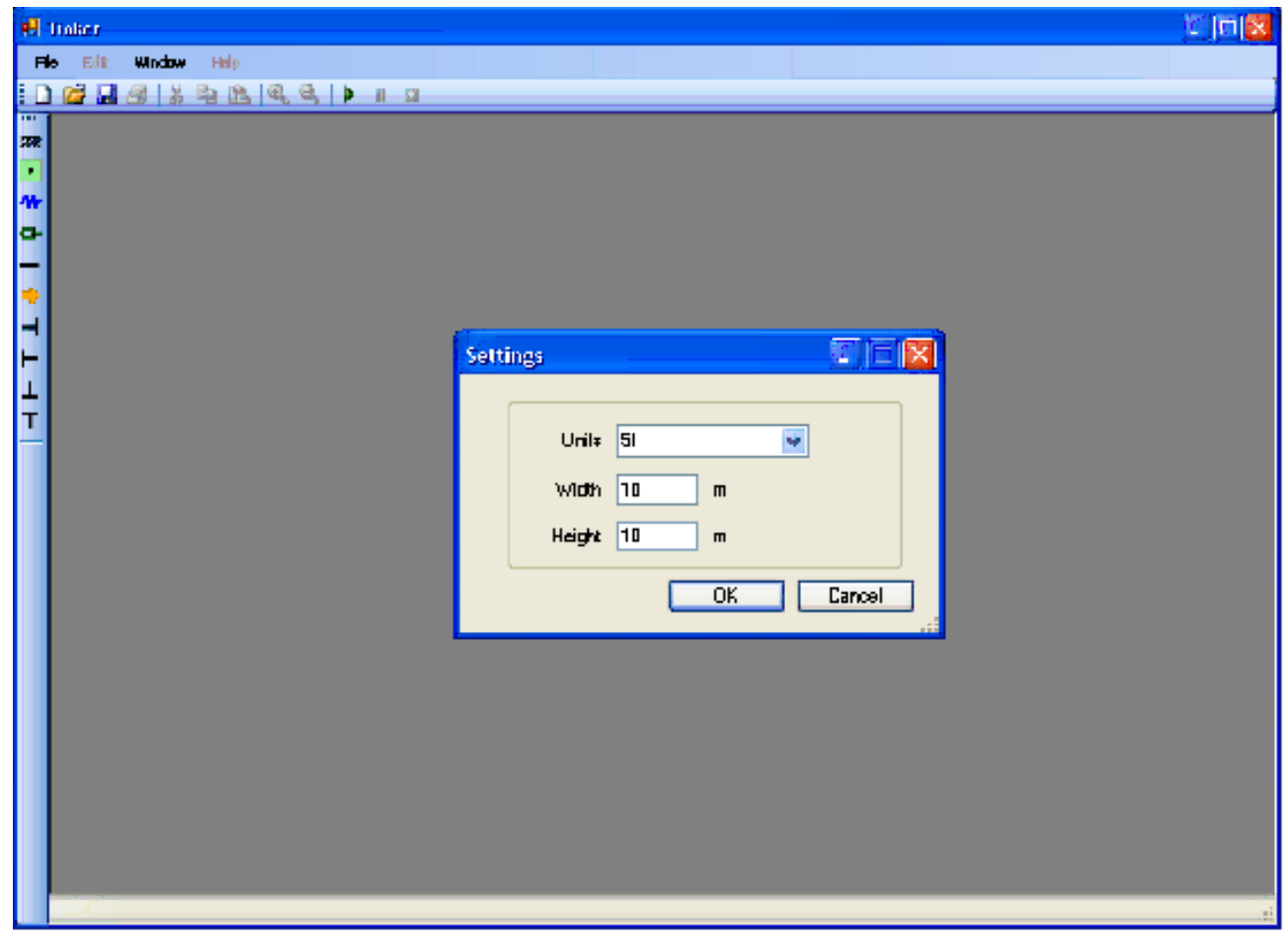

Figure 1. Opening Screen - Selecting Units and Working Grid Size 
Once preliminary settings selected, a grid is generate for the working space of the simulation. A predefined global coordinate system is shown, as well a directional arrow for gravitational forces. Students can choose to "turn-off" gravity or change its value to evaluate the impact gravity has on the system.

The software provides a "construction set" that students can use to build simulations of dynamic models and run them to observe their performance. The basic elements are shown in a toolbar on the left-side of the grid shown in Figure 2. The symbols are consistent with the standard symbols utilized in standard dynamics books and used throughout the class to work examples by hand.

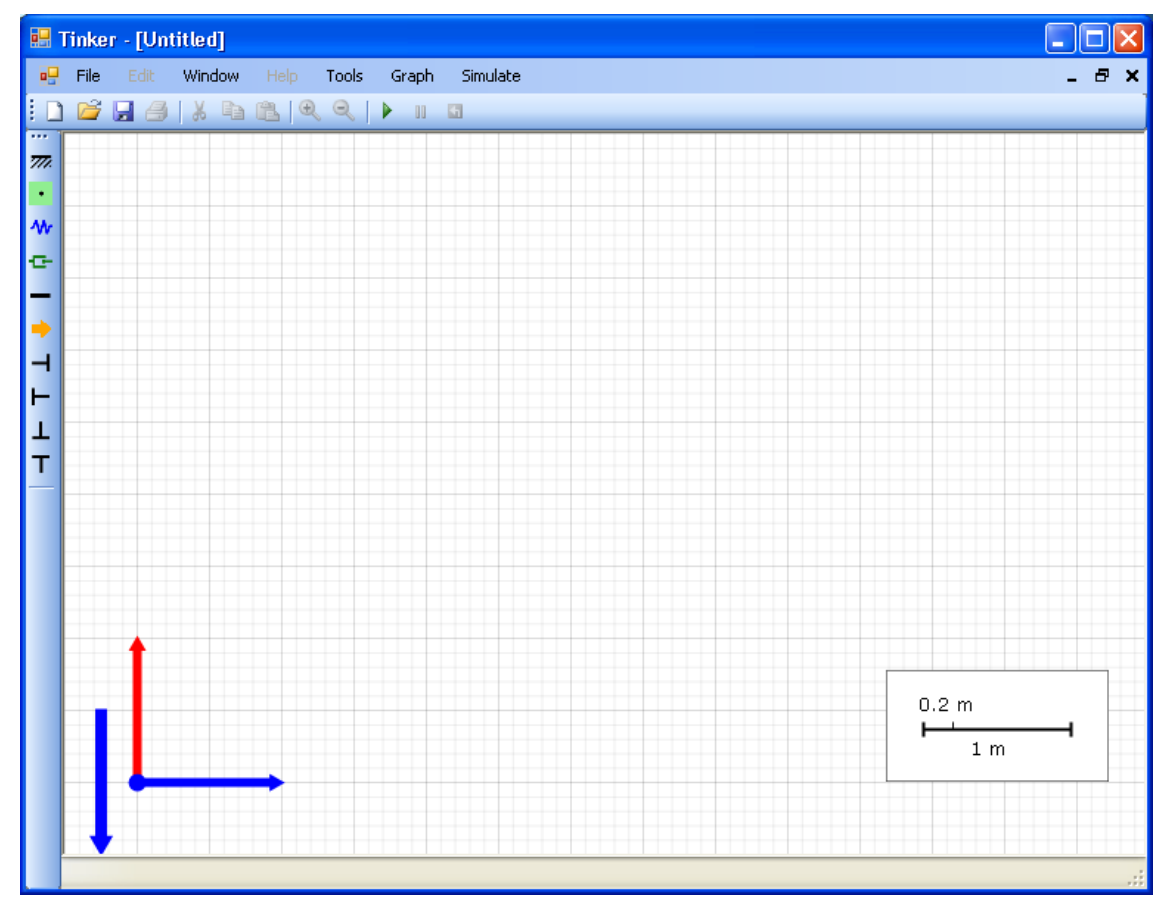

Figure 2. Working Grid-space for Developing Dynamic System

The process of "building" a model consists of clicking on an object from the toolbar on the left, dragging the object to the desired location, orienting the objects, and attaching them to each other. Once the system is assembled, the screen will appear much like a figure in a textbook (see Figure 3). Note in Figure 3 that the mass and each support are accompanied by a label as well as a "local" coordinate system. These labels reinforce the concept of coordinate systems, and their relationship to values being used or calculated in the analysis of the dynamic motion of objects in the system. 


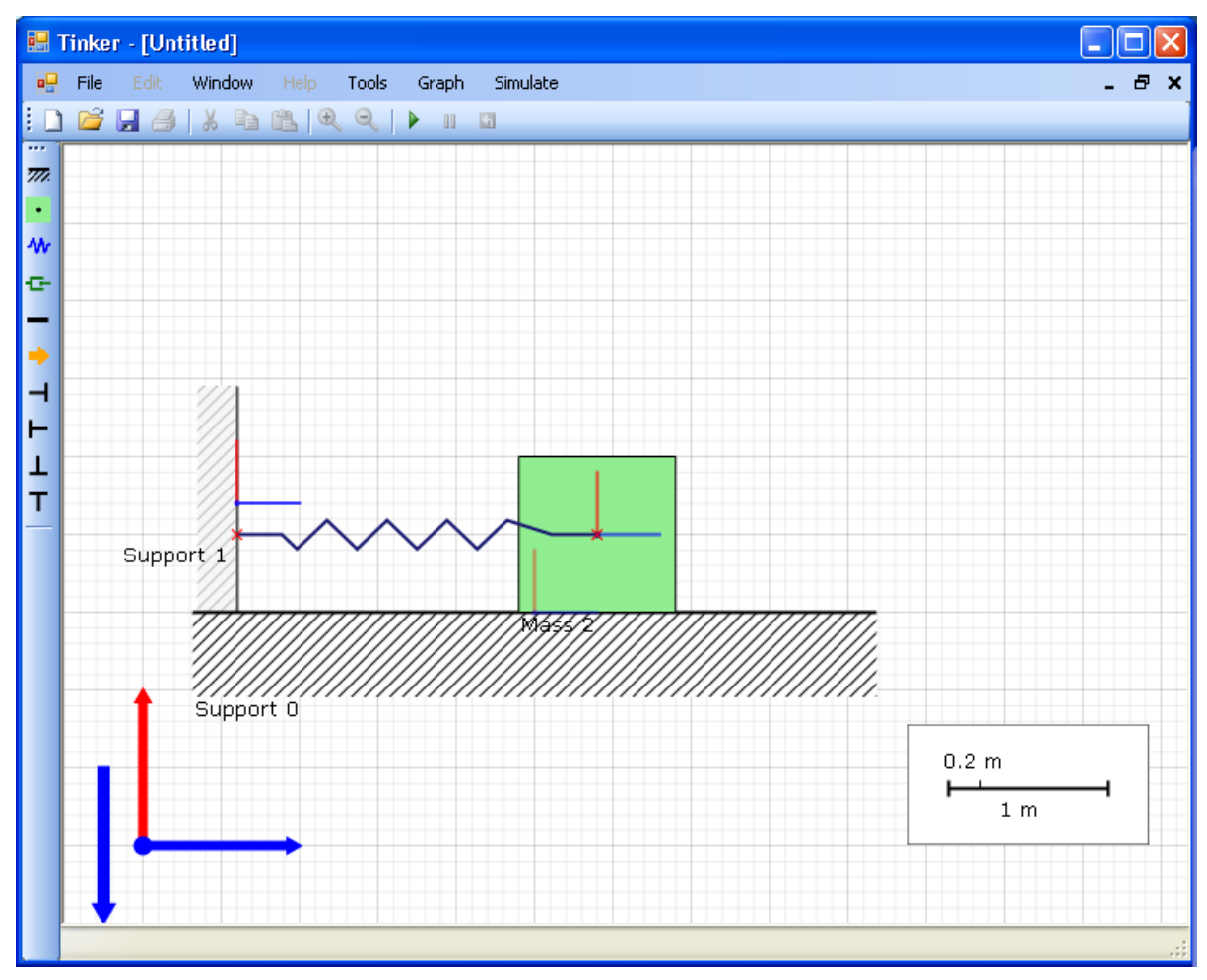

Figure 3. Working Grid-space for Developing Dynamic System

Each component of the model consists of an editable, smart element. Model properties can be tuned and modified as desired. (See Figure 4) By editing the model, a user can customize the model to match almost any textbook problem. This also allows for easy acquisition of experience through "what-if" scenarios - the same experience some of us obtained by working more problems (or simply by living longer).

Editing the model is accomplished through a Properties Box. Embedded in the list of properties are ordinary items (position, length, stiffness, etc.) as well as key concepts, such as undeformed length. Students often have difficulty with choice of coordinate system (what difference does it really make?). By changing the undeformed length, they are able to see what difference it really makes. Another traditionally difficult topic is that of ground motion. Another property of a support is the presence, magnitude and frequency of motion. Properties such as static and dynamic friction coefficients allow student to explore the relatively advanced dynamic stick-slip phenomenon. 


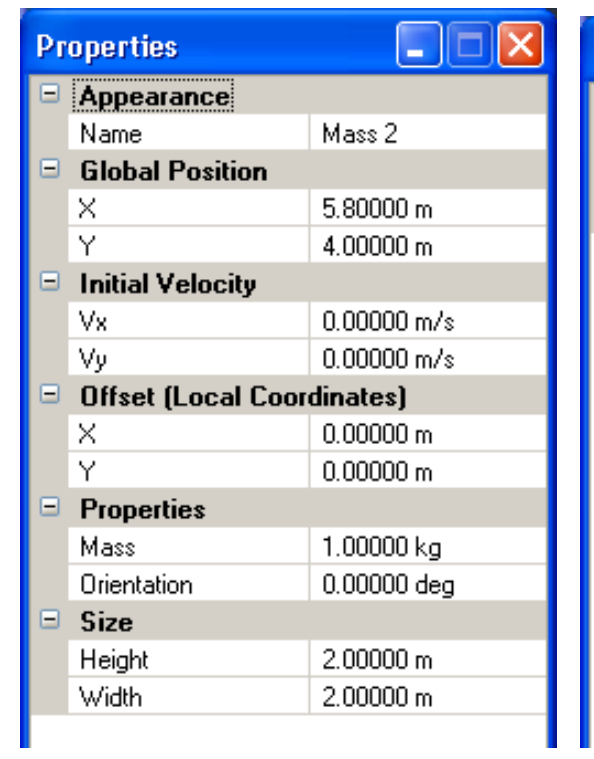

(a) Mass

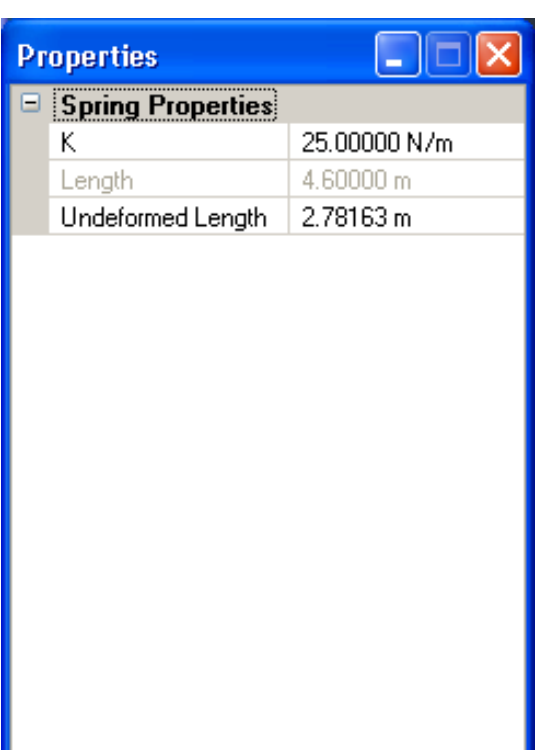

(b) Spring

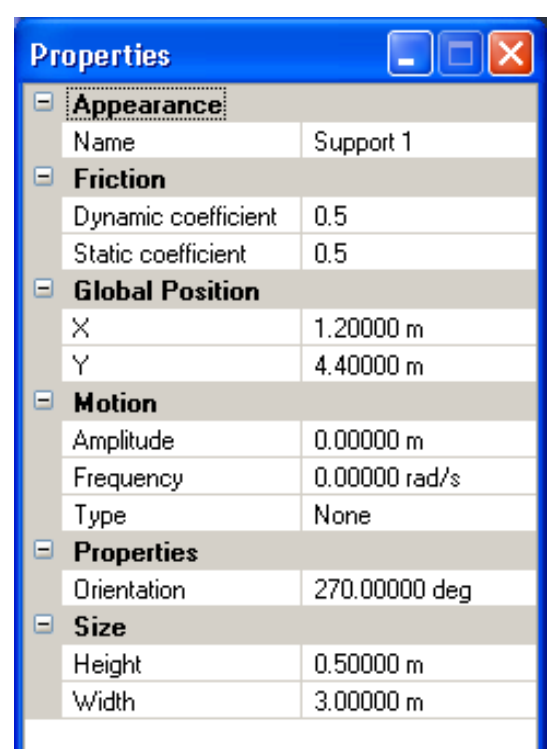

(c) Support

Figure 4. Editable Properties for Different Elements

\section{Implementation of Active Demonstrations with Software}

Demonstrations need not be extraordinarily complicated to be effective. The simple demonstrations often are very effective at helping students develop observation skills, and making reasonable assumptions. Additional equipment and instrumentation have obvious advantages (allowing easy comparisons in observed and predicted values of whatever); however, the additional expense and setup time do not add to the intrinsic value of having the students develop a good qualitative prediction of what will happen during the demo; comparing observations of the demonstration with predictions from theory. Demonstrations were developed to address concepts that had typically caused students difficulty in past semesters and to help students connect analytical solutions with the physical situations.

\section{Physical Demonstration}

One topic that students typically struggle with is the choice of reference position for the degree of freedom definition: whether to measure displacement from the un-deformed spring position or the position where the system is in static equilibrium. A simple demonstration used has a mass hanging from a spring, as illustrated in Figure 5 below. The location of static equilibrium is marked in blue while the location where the spring is un-deformed is marked in red.

The system is shown to the students and they are asked to create a simplified physical model, something like what they see in a typical textbook example definition. They are then asked to predict what the mass will do if the spring is pulled "down”. This first step typically brings out discussions about damping, and how while no physical element looks like a dashpot in the real system, some mechanism for energy loss needs to be incorporated into the models being built. 

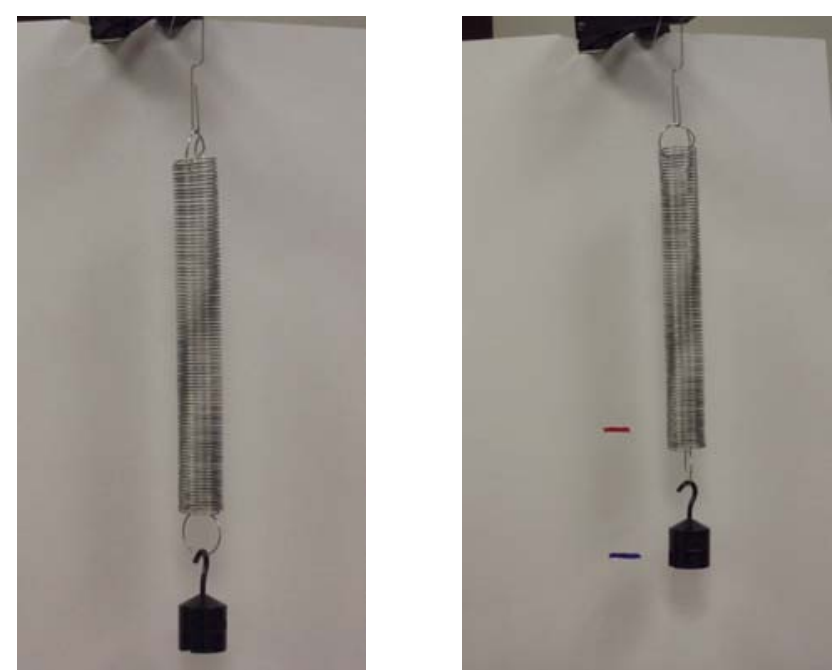

Figure 5. Demonstration of Free-Vibration Response and Coordinate System Selection

Once they have finalized their model and created a sketch of the time-history of the response, a clarifying "experiment" is conducted, like that shown in the left picture in Figure 6. This leads to a class discussion on their assumption that the initial deflection would be "straight down," which may not ever be exactly true. Class discussion also may include the ways different situations could be addressed. The demonstration is then repeated "as they assumed" with initial deformation "straight down", more like that shown in the picture on the right in Figure 6. Class discussion then includes: how the plots look when measured from the different locations; how the equations describing the results differ; and reinforce that the plots, although different, describe the same physical phenomenon.
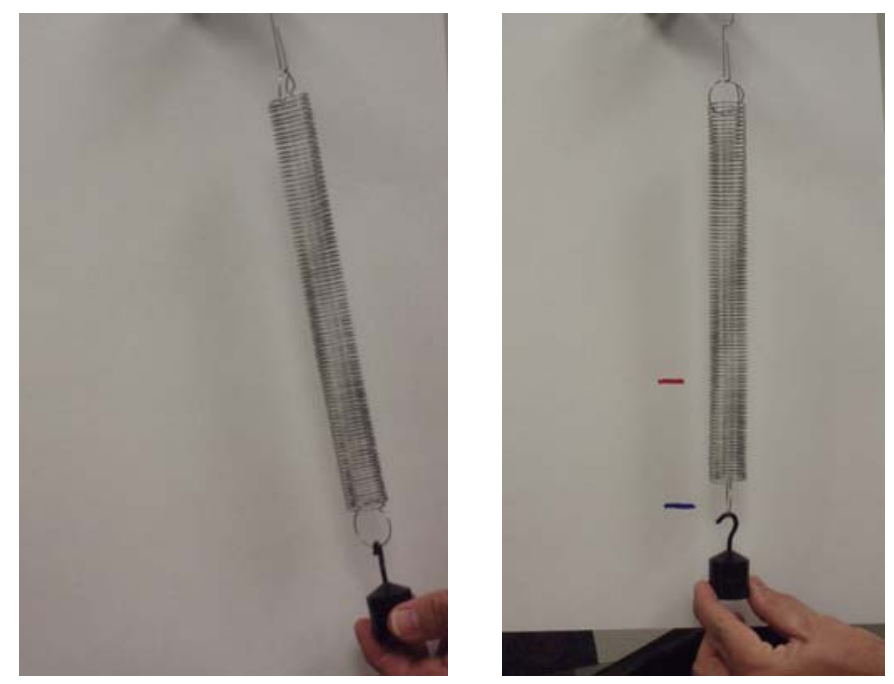

Figure 6. Repetition of Class Demonstration AFTER Initial Class Discussion 


\section{Computer Demonstration}

Although very powerful, there are limitations of physical demonstrations. Students cannot easily explore "what if" (we do not have the ability to vary length of spring, spring stiffness, mass, etc. over a large range of values. Furthermore, the connection with their mathematical results is not obvious (an analysis results in an equation; a demonstration shows how the objects move; but what does the graph look like?)

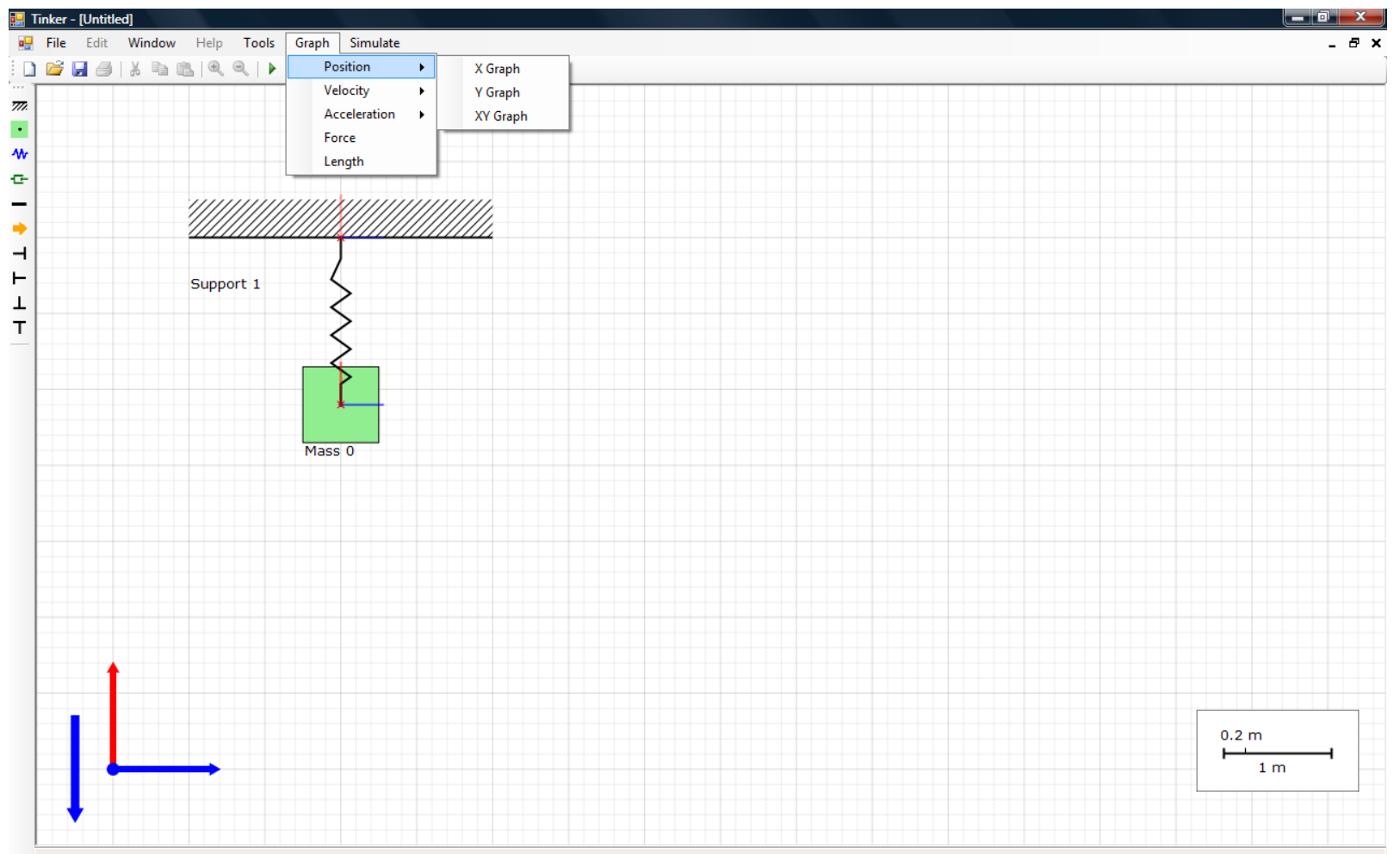

Figure 7. Graphing Menu for Vibration Simulation

The software provides options for a variety of graphs to be generated in real-time (see Figures 7 and 8). These graphs provide a convenient bridge between dynamic behavior and the equations resulting from dynamic analysis. Students are relatively more experienced relating equations to graphs. The ability to connect what they see to a graph enables them to close the gap between what they see and what the equations show them. 


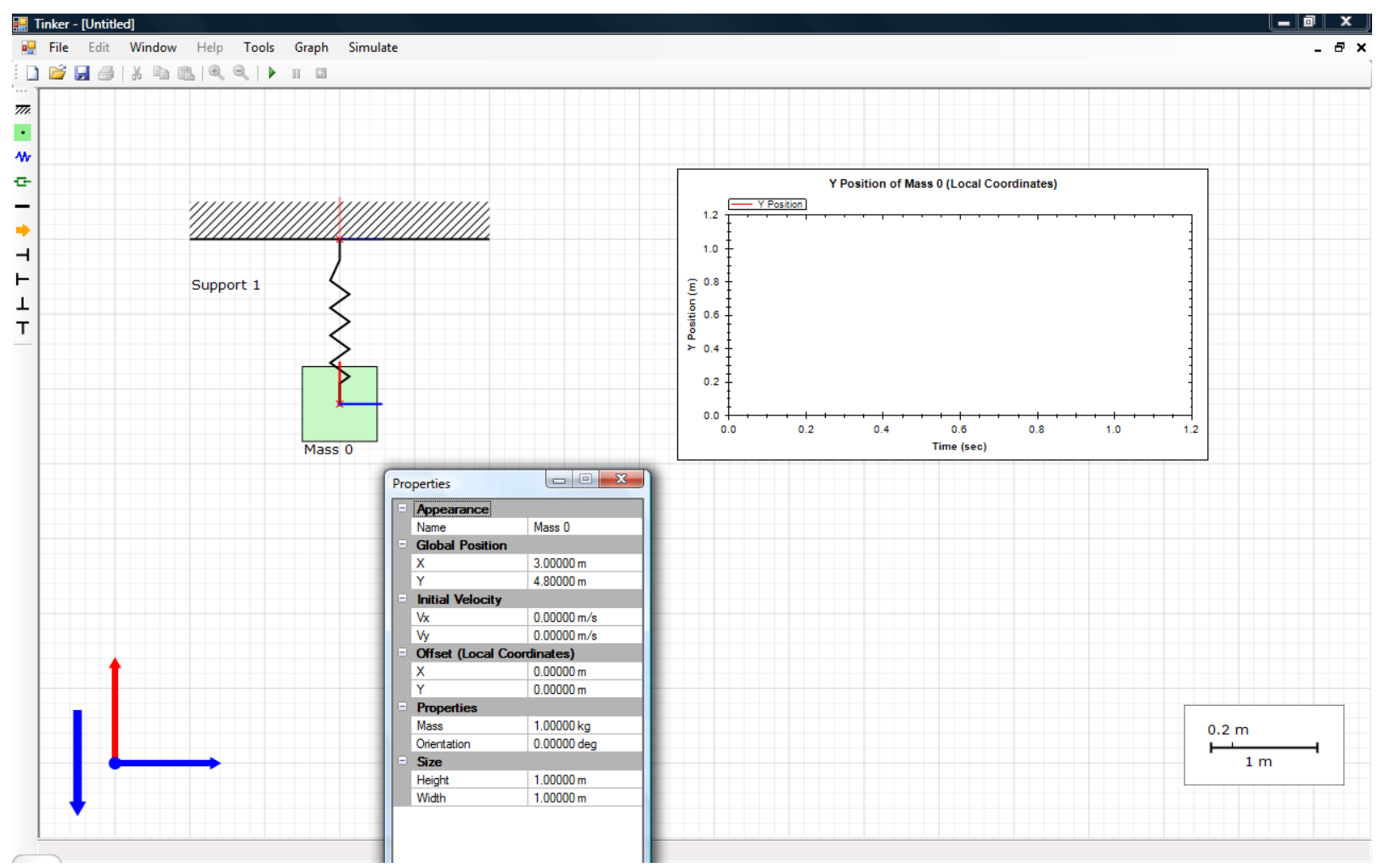

Figure 8. Displayed Plot Window and Mass Properties

Users may access the properties box for the mass element to enter desired properties, including initial conditions. The choice of coordinate systems is a topic students struggle with, as discussed earlier, and the software allows students to move the local coordinate system to any desired condition. Initial conditions are specified with respect to the local coordinate system for that mass, just as students must determine the appropriate initial conditions for solving their problem based on their degree of freedom selection.

They also have the ability to position the mass by clicking and dragging the element to any position on the working grid. The local coordinate system will travel with the mass during that process, maintaining zero initial displacement conditions relative to the local coordinates. Students also can simulate the in-class demonstration - pulling "not quite" straight down. In addition, by selection an appropriate combination of graphs (see Figure 9), begin to make sense of what appeared to be chaotic behavior during the class physical demonstration. Notice that in this case, the initial displacement conditions are zero relative to the local coordinates. The plots chosen to display are the force in the spring as well as the position in the plane relative to the local coordinates, as opposed to displacement vs. time plots 


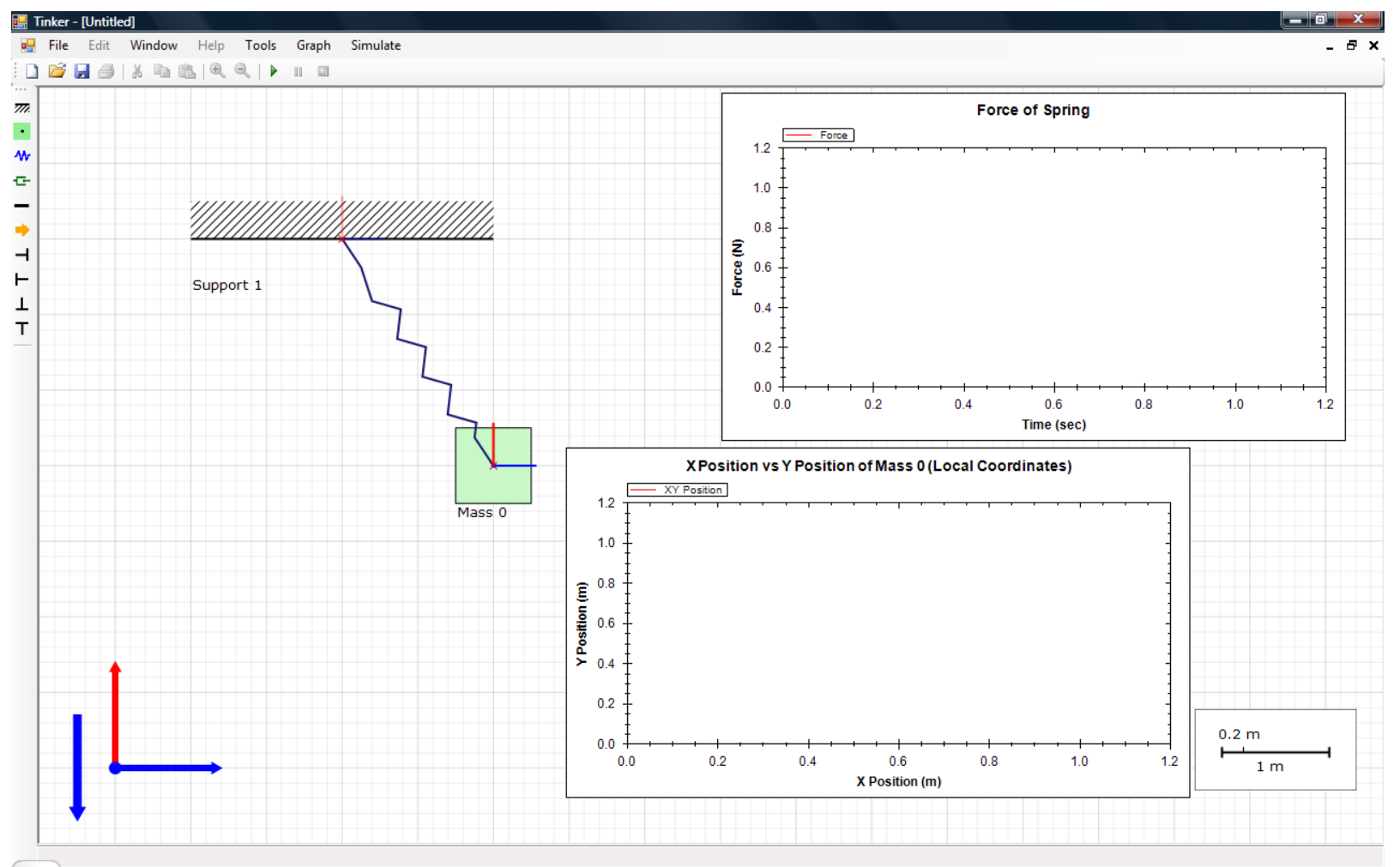

Figure 9. Repeating Physical Demo Using Simulation Software

Many students have difficulty interpreting plots of response versus time and connecting the information in the plot to either the mathematical expressions "derived in class", or to the observed response (whether physical or simulated). Once the simulation is started, the mass will "bounce" around and the selected plots are created instantaneously in "simulation time." In this way, the students can see how the information on the plots corresponds to the observed motion (Figure 10). The simulation software has a "play" and a "pause" button which allow the students to step through the response in slow-motion. This feature also permits the student to compare the location of the mass with the point on the graph at various times during the simulation.

In this example, Tinker provides the perfect bridge between single and multiple degree of freedom systems. Every student realizes that there is the swing of a pendulum combined with the up and down motion of the mass. This can be used as a segue to discussion of two degree of freedom systems, coupled equations of motion, and why are there two frequencies (eigenvalue analysis). 


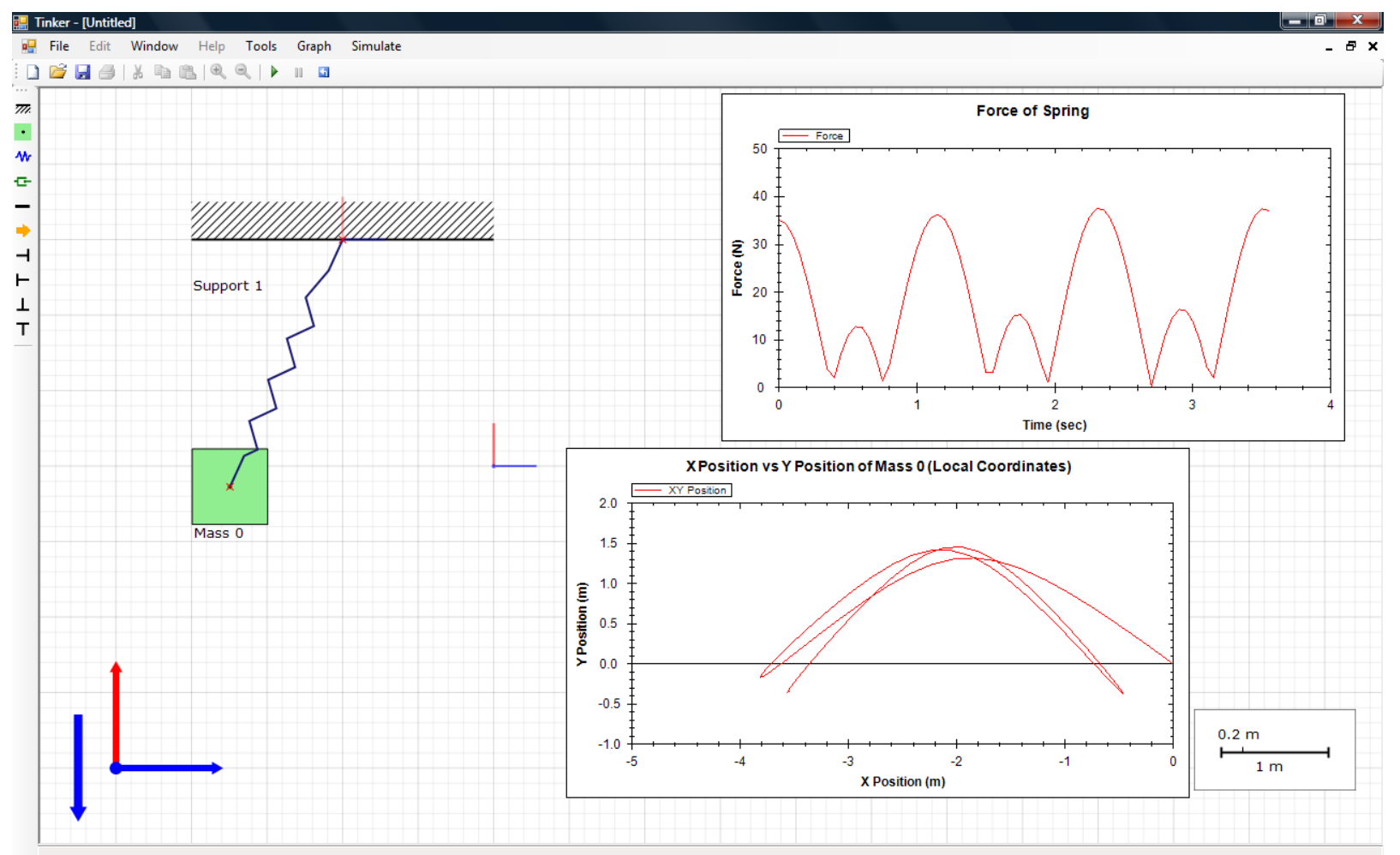

Figure 10. Screenshot of Simulation

\section{Summary and Conclusions}

The results from introducing demonstrations into the course were overwhelmingly positive. These benefits come in two forms: (1) greater enjoyment of the students and faculty, and (2) a positive impact on the learning. Introducing demonstrations generally require additional class time spent on a particular topic, requiring that fewer topics get "covered" in a semester. However, these additional topics were frequently poorly grasped by the students and not used in subsequent courses. Part of the explanation for students not grasping these more advanced topics can be linked to a weak understanding of the fundamental topics. We now get better learning of fundamentals through the use of demonstrations.

In some instances, the demonstrations actually reduce the amount of time spent on a topic. Originally, discussions on mode shapes and frequencies had to be repeated numerous times. A frequent comment from the students was that they "could do the math, but had no idea what the numbers were." With the introduction of the demo, the class quickly "sees" what a mode shape and frequency represent physically, making the math physically meaningful. 


\section{Acknowledgments}

The authors want to thank our colleagues in the Visualization Sciences, Drs. D. House and V. Srinivasan, and in particular Donald Fong for his help in developing Tinker. We also thank the Zachry Department of Civil Engineering for support of the changes in this class. This work is based upon work supported by the National Science Foundation under Grant Number 0536834. The support of NSF is gratefully acknowledged.

\section{References}

1. Childs, D “Developing A New Differential-Equation-Based Dynamics/Vibration Course,” at ASEE Gulf-Southwest Section 2001 Annual Conference: Changing the Engineering Profession, March 28-30, 2001, Texas A\&M University, College Station, TX.

2. L.R. Barroso and J. Morgan. "Replacing Rigid Body Dynamics with Dynamics \& Vibrations: A Perfect Introduction for Undergraduate Civil Engineers,” Proceedings of the 2004 ASEE Gulf-Southwest Annual Conference, Texas Tech University, Lubbock, TX. March 10-12, 2004.

3. Evans, D.L., et. al. "Panel Discussion: Progress on Concept Inventory Tools," 33rd Frontiers in Education Conference, Westminster, CO, November 5-8, 2003.

4. Lillian C. McDermott; Improving students learning in science through discipline-based education research, in "Improving Undergraduate Instruction in Science, Technology, Engineering, and Mathematics: Repost of a Workshop”, McCray, R.A., DeHaan, R., and Schuck, J.A. eds., National Research Council, Washington, DC.

5. National Research Council ; Knowing what students know: The science and design of educational assessment. Committee on the Foundations of Assessment, Pellegrino, J., Chudowsky, N., and Glaser, R. eds. Board on Testing and Assessment, Center for Education. Division of Behavioral and Social Sciences and Education. Washington, DC.

6. Marilla Sviniki ; Learning and Motivation in the Postsecondary Classroom.Anker Publishing Company, Boston, MA

7. Bransford, J. D., Brown, A. L., \& Cocking, R. R. (Eds.). How people learn: Brain, mind, experience, and school. Washington, DC: National Academy Press.

8. John Clement, Students’ preconceptions in introductory mechanics, American Journal of Physics, 50(1), January 1982.

9. Richard M. Felder and Joni Spurlin, Applications, Reliability and Validity of the Index of Learning Styles, Internalitional Journal of Engineering Education, Vol. 21, No. 1, pp 103-112, 2005

10. Margaret Fritz, Using Learning Styles Inventories to Promote Active Learning, Journal of College Reading and Learning, 32 no. 2, Spring 2002

11. Gary L. Gray, Don Evans, Phillip Cornwell, Francesco Costanzo, Brian Self "The Dynamics Concept Inventory Assessment Test: A Progress Report," Proceedings of the 2005 American Society for Engineering Education Annual Conference, Portland, OR.

12. Jennifer A. Livingston, Metacognition: An Overview, 2003 (obtained from Educational Resources Information Center, US Department of Education)

13. D.A Kolb, Experiential Learning: Experience as the Source of Learning and Development, Englewood Cliffs, N.J.: Prentice-Hall, 1984.

14. Richard M. Felder and Rebecca Brent, Understanding Students Differences, Journal of Engineering Education, 94(1), 57-72

15. Gramoll, K. “Using 'Working Model' to Introduce Design into a Freshman Engineering Course.” 1994 ASEE Conf. Proc., Edmonton, Canada, June 1994

16. Flori, R.E., Koen, M.A., and Oglesby, D.B. "Basic Engineering Software for Teaching ("BEST") Dynamics.” Journal of Engineering Education, January 1996, Vol. 85, 61-67.

17. Foley, B.J. "Designing Visualization Tools for Learning.” CHI '98: CHI 98 Conference Summary on Human Factors in Computing Systems, Los Angeles, Calif., 1998, 309-310.

18. Naps, T. (co-chair), Roessling, G. (co-chair) et al. (2003). "Evaluating the educational impact of visualization.” ITiCSE-WGR '03: Working group reports from ITiCSE on Innovation and technology in computer science education, Thessaloniki, Greece, 2003, 124-136.

Proceedings of the 2008 ASEE Gulf-Southwest Annual Conference

The University of New Mexico - Albuquerque

Copyright (C) 2008, American Society for Engineering Education 
LUCIANA R. BARROSO

Dr. Barroso currently serves as an Assistant Professor of Civil Engineering at Texas A\&M University. Her research interests include engineering education, structural control, structural health monitoring, earthquake engineering, and probabilistic hazard analysis.

\section{JIM MORGAN}

Dr. Morgan currently serves as an Associate Professor of Civil Engineering at Texas A\&M University. He is the father of two daughters and the spouse of an engineer. His research interests include structural mechanics and dynamics, earthquake engineering, and engineering education. 